\title{
Polyphenol profile and content in wild and cultivated Cynara cardunculus $L$.
}

\author{
Gaetano Pandino,, ${ }^{1,2}$ Sara Lombardo, ${ }^{1}$ Gary Williamson, ${ }^{2}$ Giovanni Mauromicale ${ }^{1}$ \\ ${ }^{1}$ Department of Agricultural and Food Science, University of Catania, Italy \\ ${ }^{2}$ School of Food Science and Nutrition, University of Leeds, UK
}

\begin{abstract}
The species Cynara cardunculus L. is native to the Mediterranean Basin, where its commercial production makes a significant contribution to the agricultural economy. It contains phenolic acids and flavones, which play an important role in diet, because of their beneficial effects on human health, and in industrial processing, due to the browning phenomenon. The quantitative and qualitative profile of these compounds is affected by different factors, such as genotype, environmental conditions, crop management and processing procedures. As a consequence, these are relevant for defining the quality of the product. Therefore, our aim was to review the main factors that influence polyphenol biosynthesis and degradation in $C$. cardunculus. From available data in literature, the genetic background appears to be the main factor, followed by environmental effects. However, crop management also could be a valuable tool to enhance the polyphenol content. C. cardunculus also provides substantial quantities of polyphenol-rich by-products, which could be considered as a natural source of health-promoting compounds and an added value for the farming business.
\end{abstract}

\section{Introduction}

Cynara cardunculus $\mathrm{L}$. is a complex species consisting of the globe artichoke [var. scolymus (L.) Fiori], the cultivated cardoon (var. altilis DC.) and the wild cardoon [var. sylvestris (Lamk) Fiori]. The three types (wild cardoon, cultivated cardoon and globe artichoke) are fully cross-compatible and inter-fertility and their $F_{1}$ hybrids are fully fertile (Basnizki and Zohary, 1994; Mauromicale and Ierna, 2000). The Cynara L. is a relatively small genus taxa (Wiklund, 1992) of the daisy family Asteraceae (ex Compositae), native to the Mediterranean region, sharing its distribution with the olive (Olea europea). C. cardunculus is a heminyptophytie, perennial rosette plant, which renews itself year after year by means of lateral shoots arising just below the soil surface. The wild type is a robust thistle with a characteristic rosette of large spiny leaves, branched flowering stems, and blue-violet flowers. In Sicily there are few areas where wild cardoon plants have white and pink flowers. The wild cardoon is distributed over the west and central part of the Mediterranean Basin (from Portugal to west Turkey), as well as The Canary Islands and Madeira. In postColumbian times, it colonized some parts of the New World and is a weed in parts of Argentina, Chile and California (Basnizki and Zohary, 1994). Crude aqueous extracts of the flowers of var. sylvestris are used in Portugal, Spain and Italy as a successful replacement for rennet in cheese making. Globe artichoke is an important vegetable in Mediterranean countries, where about $80 \%$ of the world surface (128 Kha) is cultivated. Italy (50 Kha), Spain (13 Kha), Egypt (9 Kha) and France (9 Kha) are the leading countries. In the other parts of the world, Peru (7 Kha), Chile (5 Kha), Argentina (4 Kha) and USA (3 Kha, mainly in California) are the main producers (FA0, 2012). For the first time, it has been reported in China in 2001, where 9 Kha are cultivated. The globe artichoke is widely consumed raw, boiled, steamed or fried, and used in many recipes, since it tastes good and is perceived as a healthy and nutritious vegetable, but other possible uses are: fresh and dry biomass and forage for livestock feed, preparation of alcoholic beverages and medications from leaves dry extracts and inulin extraction from roots (Foti et al., 1999; Maccarone et al., 1999; Gominho et al., 2001; Fernández et al., 2006; López-Molina et al., 2006). Globe artichoke is described in the pharmacopaea and health-promoting functions are currently reported. The cultivated cardoon has been cultivated as a vegetable since ancient times but the land area devoted to this crop has never been large (2-3000 ha), localised in Spain, Italy, France and Greece (Ierna et al., 2012). The commercial product is the enlarged petioles, central rib and a small part of the leaf border (two thirds of the inferior part of the leaf is utilized) harvested at the beginning of the winter after a bleaching period, which usually takes about one month. The plant, which can grow up to $2 \mathrm{~m}$ high, has the leaves of the basal rosette petiolata, very large, coriaceous, bright green and tomentose above and white-tomentose beneath. The stem is the floral scape as a corymbose cyme. The flowers are grouped in large globular non-edible capitula with the colour of corolla blue, lilac or whitish. 
The natural cycle and some biologic and morphologic traits of the three $C$. cardunculus botanical varieties are perfectly adapted to Mediterranean climate conditions. During their natural cycle, the seed germinates with the first rain after the dry and hot summer, plants develop a leaf rosette in autumn and pass the winter at this stage. In spring, the floral stalk develops, in May the first capitulum appears, in June flowering, and in July, the fruit ripens. The type of fruit is the cypsela (achene). Since it is an indehiscent fruit with dry pericarp that acts as a dispersal unit, the fruit of the Asteraceae is commonly called seed, in spite of the fact that the seed is only the kernel that is inside the cypsela. During the summer the parts of the plant above ground dry off and the part underground enters a dormant state until a new cycle begins with the leaf burst from the buds with the autumn rainfall. Because of its deep root system, the plant is able to extract water and nutrients from very deep soil zones and, in non-irrigation conditions, uses the rainwater accumulated during autumn, winter and early spring.

Potential health-promoting effects have been related to the polyphenols present in $C$. cardunculus (Gebhardt and Fausel, 1997; JimènezEscrig et al., 2003). Recently, the nutritional value and health-promoting properties of globe artichoke polyphenols were reviewed (Lattanzio et al., 2009; Ceccarelli et al., 2010). These compounds are affected by different factors, such as genotype, environmental conditions, crop management and processing practices. In this paper, for the first time, the main factors that influence the polyphenol biosynthesis and degradation in C. cardunculus are reviewed.

\section{Polyphenol compounds in C. cardunculus}

Polyphenols are a large group of secondary metabolites widely distributed in plants, which can be divided into two major subgroups: phenolic acids and flavonoids (Manach et al., 2004).

\section{Phenolic acids}

Phenolic acids consist of two subgroups: hydroxybenzoic and hydroxycinnamic acids. The latter chiefly consist of coumaric, caffeic and ferulic acids, that are rarely found in the free form (Manach et al., 2004). C. cardunculus species are a good source of esters of quinic acid and caffeic acid (or caffeoylquinic acids) (Figure 1). The main compounds are 5-O-caffeoylquinic acid (or chlorogenic acid) and 1,5-O-dicaffeoylquinic acid, followed by minor components (1 and 3-O-caffeoylquinic and 1,3-O-dicaffeoylquinic acids) (Schütz et al., 2004; Lattanzio et al., 2009; Lombardo et al., 2010; Pandino et al., 2010). The caffeoylquinic acids have a relevant role as structural and functional components of plant cell walls (Faulds and Williamson, 1999), as bioactive components of the human diet, and act as precursors for processes, which lead to a loss of quality (Shahidi, 1997). The quality loss is due to the browning phenomenon, which occurs through oxidative degradation by polyphenol oxidase or to formation of iron-chlorogenic acid complexes (Lattanzio et al., 1994, 2009). This phenomenon is especially important in fresh-cut products, post-harvest handling and storage, and represents a limiting factor to processing artichoke for both industrial and minimally processed products (Gimenez et al., 2003; Lattanzio et al., 2003; Todaro et al., 2010; Amodio et al. 2011). The food industry, in order to prevent enzymatic browning, have often used synthetic antioxidants, such as butylated hydroxyanisole and butylated hydroxytoluene, acidifying agents and calcium solutions, for extending shelf-life (Choi et al., 2000; Martin-Diana et al., 2007; Rico et al., 2007). However, the perceived safety problems with synthetic antioxidants led to an increased interest for the recovery and exploitation of natural antioxidants, such as caffeoylquinic acids, from agricultural and industrial waste (Heilmann et al., 1995; Fukumoto and Mazza, 2000; Peschel et al., 2006). The globe artichoke, producing a huge amount of agricultural and industrial waste $(\sim 80-85 \%$ of the total plant and $\sim 60 \%$ of the whole head, respectively), represents an important source of caffeoylquinic acids (Lattanzio et al., 2002; Llorach et al., 2002; Lombardo et al., 2010; Pandino et al., 2011b). In addition, the cardoon forms are also rich in caffeoylquinic acids (Pinelli et al., 2007; Pandino et al., 2010, 2011b). These compounds, when consumed with the diet, are well absorbed after metabolism (Manach et al., 2005; Azzini et al., $2007)$ and have been related to a decrease in risk of chronic diseases including cancer and cardiovascular disease (Kinnula and Crapo, 2004; Holst and Williamson, 2008). Nakajima et al. (2007) also reported that some caffeoylquinic acids inhibit lipid peroxidation and exhibit neuroprotective activities, while other researchers their demonstrated antiHIV (Human Immunodeficency Virus) effects and antiviral activity (McDougall et al., 1998; Slanina et al., 2001; Li et al., 2005). The caffeoylquinic acids play an important role in plant cell-walls. Faulds and Williamson (1999) reported that they are implicated in providing structural support for the plant cell-wall by bridging certain polymers in the cell-wall. This explains the high content of caffeoylquinic acids in the floral stem, which provides mechanical support of immature inflorescences of $C$. cardunculus (Pandino et al., 2011b). Moreover, they are precursors of lignin, protecting the inner parts from biotic and abiotic stressors. Consequently, this process involves a decrease of caffeoylquinic acids content, as found in the outer bracts of capitulum of globe artichoke (Fratianni et al., 2007; Lombardo et al., 2010; Pandino et al., 2011c).
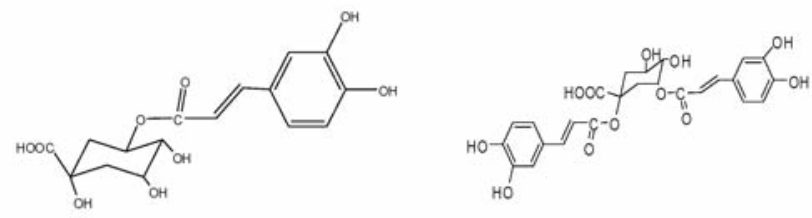

5-O-caffeoylquinic acid (chlorogenic acid) 1,3-O-dicaffeoylquinic acid (cynarin)

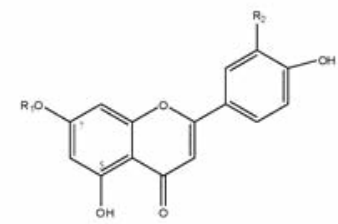

$\begin{array}{lll}\text { Luteolin 7-O- rutinoside } & \mathrm{R}_{1}=\text { rut } & \mathrm{R}_{2}=\mathrm{OH} \\ \text { Luteolin 7-O- glucoside } & \mathrm{R}_{1}=\mathrm{glc} & \mathrm{R}_{2}=\mathrm{OH} \\ \text { Luteolin 7-O-glucuronide } & \mathrm{R}_{1}=\mathrm{glr} & \mathrm{R}_{2}=\mathrm{OH} \\ \begin{array}{l}\text { Luteolin 7-O- } \\ \text { malonylglucoside }\end{array} & \mathrm{R}_{1}=\text { malonylglc } & \mathrm{R}_{2}=\mathrm{OH} \\ \text { Apigenin 7-O- rutinoside } & \mathrm{R}_{1}=\mathrm{rut} & \mathrm{R}_{2}=\mathrm{H} \\ \text { Apigenin 7-O-glucoside } & \mathrm{R}_{1}=\mathrm{glc} & \mathrm{R}_{2}=\mathrm{H} \\ \text { Apigenin 7-O-glucuronide } & \mathrm{R}_{1}=\mathrm{glr} & \mathrm{R}_{2}=\mathrm{H}\end{array}$

Figure 1. Mono- and di-caffeoylquinic acids and flavones detected in Cynara cardunculus. 


\section{Flavonoids}

Flavonoids are the largest group of plant polyphenols and consist of six subclasses: flavonols, flavones, isoflavones, flavanones, antocyanins and flavanols (Manach et al., 2004). In C. cardunculus the most representatives are flavones (apigenin, luteolin and their conjugates), followed by minor components such as flavanones (Figure 1) (Sanchez-Rabaneda et al., 2003; Schütz et al., 2004; Lombardo et al., 2010; Pandino et al., 2010). In particular, C. cardunculus represents a good source of aglycone apigenin and luteolin, since they are not distributed widely in food plants, being reported only in a restricted number of vegetables and herbs (Table 1). The main anthocyanins in globe artichoke are cyanidin glycosides (Aubert and Foury, 1981; Schütz et al., 2006). These impart the violet colour in the external bracts of certain globe artichoke genotypes and in the flowers of $C$. cardunculus, playing an important role in the appearance of fresh globe artichokes and acting as visual signals for pollinating insects (Pietta, 2000; Lattanzio et al., 2003). As for luteolin and apigenin conjugates, they also can protect plants from solar ultraviolet (UV) radiation and scavenge UV-generated ROS (reactive oxygen species) (Shirley, 1996). Apart from their roles in the ecology of plants, flavonoids are important components in the human diet, since they possess chemical radical scavenging properties (Wang et al., 1997; Einbond et al., 2004; MertensTalcott et al., 2008;Vinson et al., 1995; Van Acker et al., 1996; Brown and Rice-Evans, 1998; Pietta, 2000; Valentão et al., 2002; Jimenez-Escrig et al., 2003). Aljančić et al. (1999) have also reported antimicrobial activities of these compounds. These results were supported by Kukić et al. (2008) and Zhu et al. (2004), who investigated $C$. cardunculus extracts against tested strains of bacteria and fungi. Gebhardt $(1998,2001)$ observed that the aglycone luteolin inhibits cholesterol biosynthesis and biliary secretion, while Petrowicz et al. (1997) studied in vitro and in vivo the effects of artichoke leaf extract, rich in flavones, on lipoprotein metabolism. Recently, Shukla and Gupta (2010) reviewed the important role as a chemopreventive agent that the aglycone apigenin has for cancer prevention, such as breast, thyroid and colon cancer. The apigenin derivatives have antispasmodic and anti-inflammatory activities (Carle et al., 1992). In addition, the flavones exhibit other biological effects, such as inhibition of UV-induced skin carcinogenesis and vasomodulating (Birt et al., 1997; Rossoni et al., 2005), which are well documented in vitro (Williamson et al., 2005).

\section{Factors affecting polyphenol content and profile in $C$. cardunculus}

Polyphenol compounds in the plant depend upon, both quantitatively and qualitatively, environmental conditions (temperature, light, soil, etc.), crop management strategies, biotic stressors (i.e. fungi and insects), post-harvest handling, storage, industrial and domestic processing, harvest time and plant factors, such as genotype and plant part (Beckman 2000; Tomás-Barberán and Espin, 2001, Kalt, 2005; Ezekiel et al., 2011).

\section{Genotype and plant part factors}

In $C$. cardunculus, the genetic background appears to be the main factor affecting its qualitative and quantitative profile of polyphenolic compounds (Moglia et al., 2008). In the literature, there are clear examples showing the variation of total polyphenol content (TPC) and qualitative and quantitative profile amongst different globe artichoke cultivars and botanical varieties of $C$. cardunculus. Lombardo et al. (2012) analysed 17 cultivars of globe artichoke and found that the TPC in the whole head ranged from 11.9 (Spinoso di Palermo) to 58.7 (Tema 2000) $\mathrm{g}$ of chlorogenic acid equivalent (CAE) per $\mathrm{kg}$ of fresh matter (FM). Pandino et al. (2010) demonstrated a different qualitative and quantitative profile for both caffeoylquinic acids and flavones occurring amongst the capitula of three botanical varieties. In particular, a high content of caffeoylquinic acid was found in the globe artichoke [on average, $1897 \mathrm{mg}$ per kg of dry matter (DM)] and of apigenin aglycone and its derivatives in the wild and cultivated cardoon (6950 mg per $\mathrm{kg}$ of DM). In their study, it also included a Sicilian landrace (Cimiciusa di Mazzarino), which seemed closer to the cardoon form than the globe artichoke at least on the basis of phenolic composition, representing a intermediate form between wild and cultivated $C$. cardunculus (Pandino et al., 2010). Schütz et al. (2004) reported that in the globe artichoke head the most abundant compounds are chlorogenic acid, 1,5-O-dicaffeoylquinic acid and apigenin-7-O-glucuronide. The latter was the only predominant compound in the capitula of cardoon forms (Pandino et al., 2010). Schütz et al. (2006) also characterised and quantified the anthocyanins in heads of six artichoke cultivars. In particular, it was reported that the total anthocyanin content ranged from 8.4 to $1705 \mathrm{mg}$ per $\mathrm{kg}$ of DM. This genetic variability is reflected on the different parts of $C$. cardunculus plant. Several authors focused on the qualitative and quantitative polyphenol profile of leaves, due to their use for hepatoprotection, as choleretic and diuretic (Kirchhoff et al., 1994). Pinelli et al. (2007) quantified caffeoylquinic acids and flavonoids in wild and cultivated cardoon leaves, which exhibited a large variation among the analysed accessions. In a study carried out on leaf stalks of cultivated cardoon, Lahoz et al. (2010) observed a significant variation in both free and total polyphenols (10.9-90.0 and 63.5-155.5 $\mu \mathrm{mol}$ catechin 100 per g of FM, respectively). Similar results, including the globe artichoke, were reported by other authors (Romani et al., 2006; Wang et al., 2003; Pandino et al., 2011b). By a comparison of the TPC in 17 globe artichoke cultivars, Lombardo et al. (2012) reported a great variability of TPC in the floral stem (from 1.2 to

Table 1. Apigenin and luteolin aglycone contents in food herbs and vegetables.

\begin{tabular}{|c|c|c|c|}
\hline Plant source & Apigenin & Luteolin & Reference \\
\hline \multicolumn{4}{|l|}{ Herbs } \\
\hline Mint & 18-99* & $11-42^{*}$ & Justensen and Knuthsen, 2001 \\
\hline Oregano & $2-4^{*}$ & $0-3^{*}$ & Justensen and Knuthsen, 2001 \\
\hline \multirow[t]{2}{*}{ Parsley } & $510-630 *$ & $0-4^{*}$ & Justensen and Knuthsen, 2001 \\
\hline & $185^{*}$ & $1.1^{*}$ & Justensen et al., 1998 \\
\hline Sage & - & $11^{\circ}$ & Karakaya and Nehir, 1999 \\
\hline \multicolumn{4}{|l|}{ Vegetables } \\
\hline Celery leaf & $75^{*}$ & $20^{*}$ & Justensen et al., 1998 \\
\hline Celery stalk & $1.6^{*}$ & $0.5^{*}$ & Justensen et al., 1998 \\
\hline Sweet green pepper & - & $0.5^{*}$ & Justensen et al., 1998 \\
\hline Sweet red pepper & - & $0.1^{*}$ & Justensen et al., 1998 \\
\hline Sweet yellow pepper & - & $0.2^{*}$ & Justensen et al., 1998 \\
\hline Red bell pepper & - & $11^{\#}$ & Hertog et al., 1992 \\
\hline White celery stalks & $0-104^{\S}$ & $0-40^{\S}$ & Crozier et al., 1997 \\
\hline Green celery hearts & $191^{\S}$ & $35^{\S}$ & Crozier et al., 1997 \\
\hline White celery hearts & $17^{\S}$ & $6.6^{\S}$ & Crozier et al., 1997 \\
\hline $\begin{array}{l}\text { Globe artichoke } \\
\text { (receptacle) }\end{array}$ & $257-687^{\wedge}$ & Trace- $34^{\wedge}$ & Pandino et al., 2011c \\
\hline $\begin{array}{l}\text { Cultivated cardoon } \\
\text { (leaves) }\end{array}$ & $1300^{\wedge}$ & $900^{\wedge}$ & Pandino et al., 2010 \\
\hline
\end{tabular}


17.6 g CAE per kg of FM) and in the receptacle (from 2.4 to $11.3 \mathrm{~g} \mathrm{CAE}$ per $\mathrm{kg}$ of FM). In the receptacle of cultivated cardoon the TPC was $\sim 20$ times lower than globe artichoke (Fratianni et al., 2007), highlighting the genetic distance between the globe artichoke and cardoon forms, as reported in the literature (Lanteri et al., 2004). According to the HPLC profile, similar conclusions were drawn by Pandino et al. (2011b), who found that floral stems of the cardoon forms are richer than the globe artichoke in the total amount of apigenin and its derivatives (on average, $0.33 \mathrm{~g}$ per $\mathrm{kg}$ of DM). Regards to the receptacle, it is interesting to note this genetic variability, representing an useful tool to define its aptitude for a specific use (fresh market or food processing), and for breeding new varieties. In this respect, Bonasia et al. (2010) analysed new seed-propagated globe artichoke cultivars, in order to define their better end-use. These authors reported that the hybrids had in the hearth (receptacle and inner bracts) the lowest TPC [on average, $2.5 \mathrm{~g}$ of gallic acid equivalent (GAE) per kg of FM] compared to the standard cultivated varietal types (on average, $5.1 \mathrm{~g} \mathrm{GAE}$ per kg of FM). Similar results were found by Lombardo et al. (2012), where the TPC of standard cultivated varietal types in the hearth was higher than hybrids (on average, 6.2 and $4.7 \mathrm{~g}$ CAE per $\mathrm{kg}$ of DM, respectively). The same trend was achieved for both outer and inner bracts (Lombardo et al. 2012).

Regardless of genotype, Lombardo et al. (2009) demonstrated that the TPC of globe artichoke is affected by plant part. In particular, the floral stem had the highest TPC, followed by the receptacle, while the outer bracts had the lowest (Figure 2). In terms of polyphenol profile, it is interesting to note the massive decrease of caffeoylquinic acids from inner to outer bracts reported by Pandino et al. (2011b, 2011c), as well as the wide variation amongst the genotypes in terms of total caffeoylquinic acids, total luteolin and total apigenin content (Figure 3). Lombardo et al. $(2010,2012)$ characterised the polyphenol profile in several globe artichoke cultivars and found that the outer bracts accumulated preferentially apigenin and its derivatives, while inner bracts and receptacle had a good content of both caffeoylquinic acids and flavones. Fratianni et al. (2007) have also demonstrated that single polyphenols are localised in specific parts of the heads. Romani et al. (2006) estimated the polyphenol composition of the different plant parts and observed that leaves contain the highest amount of flavonoids, while they are completely lacking in the floral stems. Falleh et al. (2008) studied a Tunisian cardoon type and recorded the lowest TPC in the flowers compared to leaves and seeds. In another study, Pandino et al. (2011a, 2011b) investigated the polyphenol profile in leaf and floral stem of $C$. cardunculus genotypes. In leaves, the flavones were the major compounds, whereas in the floral stem, caffeoylquinic acids were the most abundant, presumably related to their different roles in the plant.

\section{Environmental factors}

Besides the role in the plant, the concentration of flavones and caffeoylquinic acids is linked to the environmental conditions, such as light exposure. Pinelli et al. (2007) studied the effect of the light on two cultivated cardoons and observed a low amounts of flavones compared to the samples not exposed to the light. The light, mainly ultraviolet (UV), affects the different classes of polyphenols in $C$. cardunculus, as reported by Pandino et al. (2011b). These authors found that in the leaves of globe artichoke the luteolin derivatives were the main compounds, whereas in cardoon forms, apigenin derivatives were the most abundant. Moglia et al. (2008) observed in the leaves of globe artichoke a significant increase in the content of the main dicaffeoylquinic acids upon UV-C irradiation. The TPC is also affected by meteorological conditions, such as rainfall level and temperatures, as described by Lombardo et al. (2009) in a two-year experiment on the whole globe artichoke head. In particular, it was reported that the different weather conditions recorded during the harvest period of the first growing season, represented mainly by the highest average maximum temperatures and the greater quantity of rainfall, are presumably more favourable to polyphenol biosynthesis for most of the genotypes (Figure 4).

\section{Plant age and harvest time factors}

Wang et al. (2003) showed a significant variation in TPC between young and mature heads (on average, 2.8 and $1.9 \%$ of $\mathrm{DM}$, respectively). Fratianni et al. (2007) compared the obtained data on the leaf content of caffeoylquinic acids and flavones with those reported by Wang et al. (2003) and underlined that the discrepancy among these data were due to different leaf ages. In contrast, Lutz et al. (2011) did not observe significant difference in TPC between mature (diameter of 11 $\mathrm{cm}$ ) and baby (diameter of $4.5 \mathrm{~cm}$ ) globe artichoke.

Lombardo et al. (2010) characterised the polyphenol profile of globe artichoke cultivar (Romanesco clone $C_{3}$ ) in relation to harvest time (winter and spring harvest) and plant part. Their results demonstrated that the polyphenol content increased from winter to spring harvest,

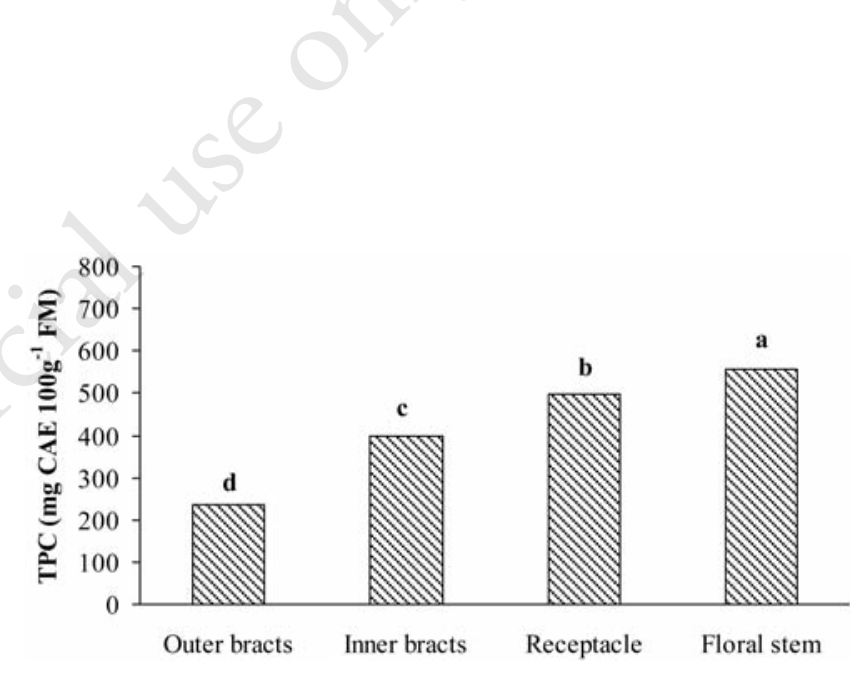

Figure 2. Total polyphenols content (TPC) of globe artichoke as affected by head fraction. CAE, chlorogenic acid equivalent; FM, fresh matter. Different letters indicate statistical significance at $\mathbf{P} \leq \mathbf{0 . 0 5}$ (adapted from Lombardo et al., 2009).

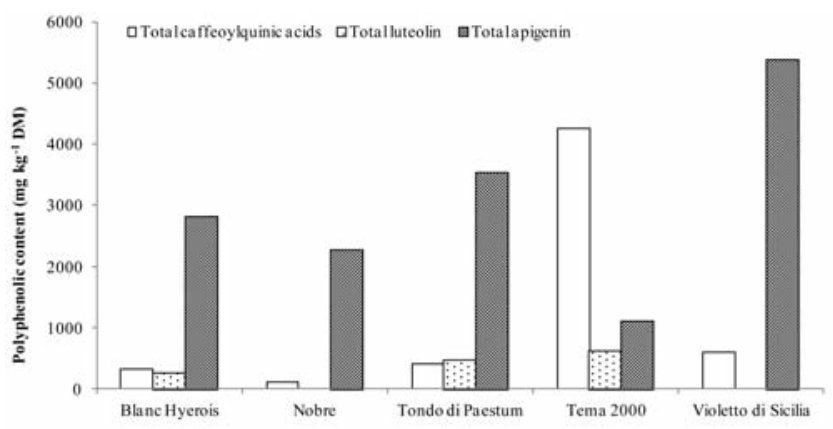

Figure 3. Total caffeoylquinic acids, total luteolin and total apigenin of globe artichoke receptacle as affected by genotype (adapted from Pandino et al., 2011c). DM, dry matter. 
particularly in the floral stem for both caffeoylquinic acids and luteolin derivatives and in the receptacle for apigenin derivatives (Figure 5). Todaro et al. (2010) also reported a higher TPC in spring than in winter (on average, 8.1 and $1.5 \mathrm{mg}$ of CAE per $\mathrm{g}$ of FM, respectively), in a study carried out on heads of three globe artichoke cultivars.

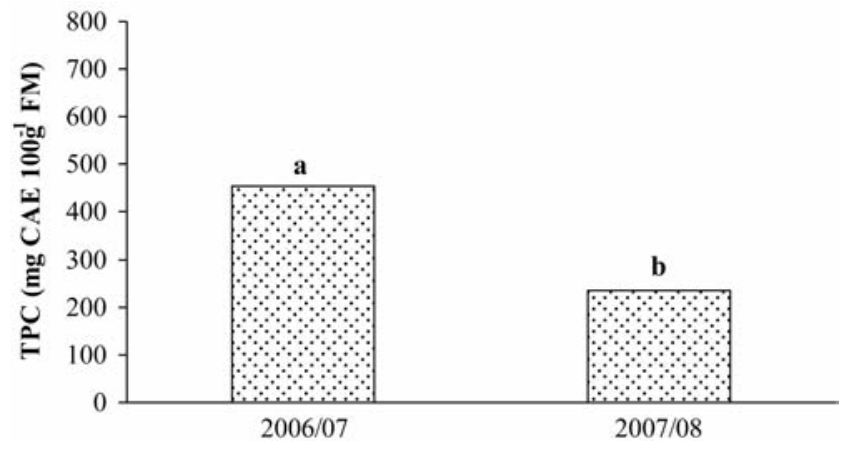

Figure 4. Total polyphenols content (TPC) of the whole globe artichoke head as affected by season conditions. CAE, chlorogenic acid equivalent; FM, fresh matter. Different letters indicate statistical significance at $\mathbf{P} \leq \mathbf{0 . 0 5}$ (adapted from Lombardo et al. 2009).

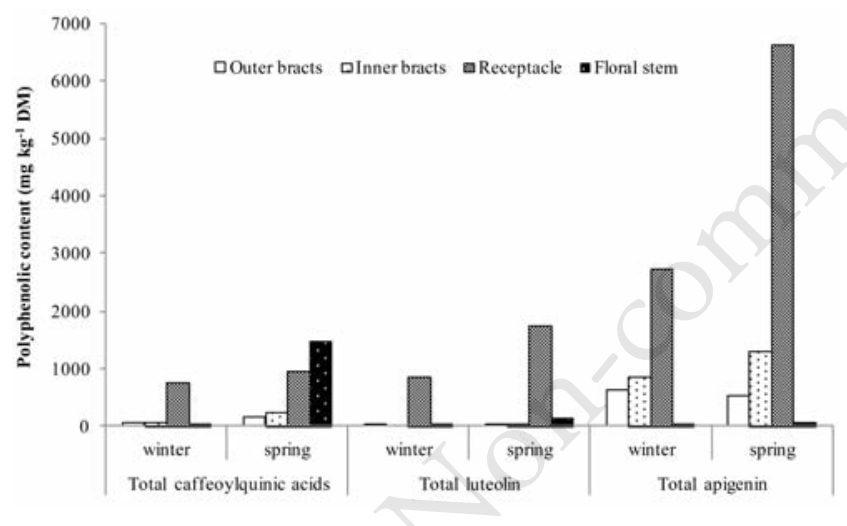

Figure 5. Total caffeoylquinic acids, luteolin and apigenin of globe artichoke in relation harvest time and plant part (adapted from Lombardo et al., 2010). DM, dry matter.

Table 2. Total polyphenols content of the whole globe artichoke head in relation to plant arrangements and planting density (adapted from Lombardo et al., 2009).

\begin{tabular}{|c|c|c|c|c|c|}
\hline \multirow{2}{*}{$\begin{array}{l}\text { Plant arrangement } \\
(\mathrm{Pa})\end{array}$} & \multicolumn{4}{|c|}{$\begin{array}{l}\text { Planting density (Pd) } \\
n \mathrm{n} \mathrm{m}^{-2}\end{array}$} & \multirow[t]{2}{*}{ Mean } \\
\hline & & 1.2 & $\begin{array}{l}1.4 \\
0 \mathrm{~g}^{-1}\end{array}$ & & \\
\hline Single row & 482 & 486 & 482 & 553 & 501 \\
\hline Twin rows & 406 & 501 & 567 & 790 & 566 \\
\hline Mean & 444 & 493 & 524 & 671 & $\mathrm{~L}^{* * *} \mathrm{QNS}$ \\
\hline
\end{tabular}

\section{Crop management factors}

With regard to the effect of crop management practices on the content of polyphenols, Lombardo et al. (2009) focused on the plant arrangement (single and twin rows) and density (1.0, 1.2, 1.4 and 1.8 plant $\mathrm{m}^{2}$ ) and found that the TPC increased from lower to higher plant density, mainly in the twin rows (Table 2). In addition, they observed a significant planting density $\times$ head parts interaction, particularly in the inner bracts, where the TPC increased 108\% from the lower to the higher plant density. Sharaf-Eldin et al. (2007) studied the possible interaction between gibberellic acid, supplied to the plants during the crop cycle used to shorten time to harvest for globe artichoke field plants, and the content of 2 phenolic acids (chlorogenic acid and 1,5-Odicafeoylquinic acid) in leaves and receptacle of globe artichoke both grown from field transplants and by direct field seeding. They observed an increase of chlorogenic acid in leaves of globe artichoke grown from field transplants, while no significant differences were found for 1,5-Odicafeoylquinic acid, as well for the receptacle in both types of field trials. In contrast, El-Abagy et al. (2010) showed significant increment in total polyphenols in the flower heads when the leaves were treated with gibberellic acid and salicylic acid, while the putrescine did not affect the polyphenol content.

\section{Handling and storage factors}

As reported by Lattanzio et al. (1994), the polyphenol content in the globe artichoke is affected also by post-harvest handling and storage conditions. During postharvest handling the globe artichoke tissue could be subjected to mechanical damages, leading to activation of polyphenol oxidase (PP0). This enzyme oxidizes phenolic acids and, therefore, reduces their amount by producing melanins (brown polymers). These authors also reported that during storage of artichoke heads at $4^{\circ} \mathrm{C}$ the activity of the enzyme phenylalanine ammonia-lyase (PAL) is stimulated, consequently leading to a biosynthetic increase of phenolic acids, especially chlorogenic acid. On the other hand, this increase becomes a good substrate for PPO (Shahidi, 1997). Since globe artichokes are usually cooked before eating, some authors evaluated the effect of cooking on the content of polyphenol compounds. In this respect, Ferracane et al. (2008) achieved an increase of $\sim 2$ times for the total caffeoylquinic acids and a decrease of $40 \%$ for the total apigenin derivatives from the raw to cooked globe artichoke. Lutz et al. (2010) also observed a significant increase of caffeoylquinic acids after cooking, in agreement with the findings of other authors, which estimated the TPC after water blanching (Llorach et al., 2002; Schütz et al. 2004; Peschel et al., 2006). This increase is probably due to the inactivation of the PPO by blanching, preserving the content of phenolic acids.

\section{Conclusions}

The studies of polyphenols in $C$. cardunculus that have been conducted to date provide a good indication of their qualitative and quantitative variation. Available evidence suggests that the qualitative and quantitative polyphenol profile appears to be strongly influenced by a high degree of heterozygosity inside of $C$. cardunculus. This has made it possible to conserve genetic variability, but on the other hand, the importance of genetic control on polyphenol content for the industrial processing has led to the development of new cultivars, which have low polyphenol content. Another approach was to work on a breeding programme in order to improve the total polyphenol content for cultivars 
destined for fresh consumption or decrease it with advantages for food processing (Pandino et al., 2011a). Recently, we selected by breeding between artichoke and cardoon forms some genotypes, which have a content of polyphenols about 10 times higher than their parents. However, given the practical difficulties of ex situ germplasm conservation in this species, a strategy of clonal selection may be the optimum route for enhancing current landraces, while at the same time conserving them in situ (Pandino et al., 2012). In addition to genetic factors, environmental conditions seem also to affect the polyphenol profile. These, combined with breeding programmes, might be a powerful tool to manipulate the polyphenol content in relation to the end-use (fresh consumption, industrial processing, pharmaceutical purposes, etc.) of a specific genotype and specific part of plant of $C$. cardunculus. A better knowledge of these correlations will be of great help in investigating the high variability of polyphenols. This review also reports that crop management practices (e.g. plant density and harvest time), cooking procedures and storage conditions affect the polyphenol content of C. cardunculus. As a general role, the cooking methods increase the qualitative and quantitative polyphenol profile, while concerning the other factors no uniform trend is noticeable, as especially observed for the crop management practices. Overall, this review demonstrates, according to the available data in the literature, the role of $C$. cardunculus as good source of phenolic acids and flavones, encouraging a wider cultivation and consumption of this vegetable not only in the Mediterranean area, but all over the world.

\section{References}

Aljančić I, Vajs V, Menkovic N, Karadzic I, Juranic N, Milosavljevic S, Macura S, 1999. Flavones and Sesquiterpene Lactones from Achillea atrata subsp. multifida: Antimicrobial Activity. J. Nat. Prod. 62: 909-911.

Amodio ML, Cabezas-Serrano AB, Peri G, Colelli G, 2011. Post-cutting quality changes of fresh-cut artichokes treated with different antibrowning agents as evaluated by image analysis. Postharvest Biol. Tec. 62: 213-220.

Aubert S, Foury C, 1981. Coleur et pigmentation anthocyanique de l'artichaut (Cynara scolymus L.). pp 57-76 in Atti III Congr. Int. Studi Carciofo, Bari, Italy.

Azzini E, Bugianesi R, Romano F, Di Venere D, Miccadei S, Durazzo A, Foddai MS, Catasta G, Linsalata V, Maiani G, 2007. Absorption and metabolism of bioactive molecules after oral consumption of cooked edible heads of Cynara scolymus L. (cultivar Violetto di Provenza) in human subjects: a pilot study. Brit. J. Nutr. 97:963969.

Basnizki Y, Zohary D, 1994. Breeding of seed planted artichoke. Plant Breed. Rev. 12:253-269.

Beckman CH, 2000. Phenolic-storing cells: keys to programmed cell death and periderm formation in wilt disease resistance and in general defence responses in plants?. Physiol. Mol. Plant Pathol. 57:101-110.

Birt DF, Hendrich S, Wang W, 2001. Dietary agents in cancer prevention: flavonoids and isoflavonoids. Pharmacol. Therapeut. 90: 157177.

Bonasia A, Conversa G, Lazzizera C, Gambacorta G, Elia A, 2010. Morphological and qualitative characterisation of globe artichoke head from new seed-propagated cultivars. J. Sci. Food Agric. 90:2689-2693.

Brown JE, Rice-Evans CA, 1998. Luteolin-rich artichoke extract protects low density lipoprotein from oxidation in vitro. Free Rad. Res. 29: 247-255.

Carle R, Gomaa K, 1992. Chamomile: A pharmacological and clinical profile. Drugs Today 28: 559-565.

Ceccarelli N, Curadi M, Picciarelli P, Martelloni L, Sbrana C, Giovannetti M, 2010. Globe artichoke as a functional food. Mediterr. J. Nutr. Metab. 3:197-201.

Choi HS, Song LS, Ukeda L, Sawamura M, 2000. Radical-scavenging activities of citrus essential oils and their components: detection using 1,1-diphenyl-2-picrylhydrazyl. J. Agr. Food Chem. 48:41564161.

Crozier A, Lean MEJ, McDonald MS, Black C, 1997. Quantitative analysis of the flavonoid content of commercial tomatoes, onions, lettuce, and celery. J. Agr. Food Chem. 45:590-595.

Einbond LS, Reynertson KA, Luo, X, Basile MJ, Kennelly EJ, 2004. Anthocyanin antioxidants from edible fruits. Food Chem. 84:23-28.

El-Abagy HMH, Rashad El-ShM, Abdel-Mawgoud AMR, El-Greadly NHM, 2010. Physiological and biochemical effects of some bioregulators on growth, productivity and quality of artichoke (Cynara scolymus L.) plant. Res. J. Agric. Biol. Sci. 6:683-690.

Ezekiel R, Singh N, Sharma S, Kaur A, 2011. Beneficial phytochemicals in potato - a review. Food Res. Int. doi:10.1016/j.foodres. 2011.04.025.

Falleh H, Ksouri R, Chaieb K, Karray-Bouraoui N, Trabelsi N, Boulaaba M, Abdelly C, 2008. Phenolic composition of Cynara cardunculus L. organs, and their biological activities. C. R. Biol. 331:372-379.

FA0, 2012. Statistical Database. Available from: http://www.faostat.org/

Faulds CB, Willimason G, 1999. The role of hydroxycinnamates in the plant cell wall. J. Sci. Food Agr. 79:393-395.

Fernández J, Curt MD, Aguado PL, 2006. Industrial applications of Cynara cardunculus L. for energy and other uses. Ind. Crops Prod. 24:222-229.

Ferracane R, Pellegrini N, Visconti A, Graziani G, Chiavaro E, Miglio C, Fogliano V, 2008. Effects of different cooking methods on antioxidant profile, antioxidant capacity, and physical characteristics of artichoke. J. Agr. Food Chem. 56:8601-8608.

Foti S, Mauromicale G, Raccuia SA, Fallico B, Fanella F, Maccarone E, 1999. Possible alternative utilization of Cynara spp. I. Biomass, grain yield and chemical composition of grain. Ind. Crops Prod. 10:219-228.

Fratianni F, Tucci M, De Palma M, Pepe R, Nazzaro F, 2007. Polyphenolic composition in different parts of some cultivars of globe artichoke (Cynara cardunculus L. var. scolymus (L.) Fiori). Food Chem. 104:1282-1286.

Fukumoto LR, Mazza G, 2000. Assessing antioxidant and prooxidant activities of phenolic compounds. J. Agr. Food Chem. 48:3597-3604.

Gebhardt R, 1998. Inhibition of cholesterol biosynthesis in primary cultured rat hepatocytes by artichoke (Cynara scolymus L.) extracts. J. Pharmacol. Exp. Ther. 286:1122-1128.

Gebhardt R, 2001. Anticholestatic activity of flavonoids from artichoke (Cynara scolymus L.) and of their metabolites. Med. Sci. Monitor 7:316-320.

Gebhardt R, Fausel M, 1997. Antioxidant and hepatoprotective effects of artichoke extracts and costituents in cultured rat hepatocytes. Toxicol. in Vitro 144:279-286.

Giménez M, Olarte C, Sanz S, Lomas C, Echàvarri JF, Ayala F, 2003. Relation between spoilage and microbiological quality in minimally processed artichoke packaged with different films. Food Microbiol. 20:231-242.

Gominho J, Fernandez J, Pereira H, 2001. Cynara cardunculus L- a new fibre crop for pulp and paper production. Ind. Crops Prod. 13:1-10.

Heilmann J, Merfor, I, Weiss M, 1995. Radical scavenger activity of different 3',4'-dihydroxyflavonols and 1,5-dicaffeoylquinic acid studied by inhibition of chemiluminescence. Planta Med. 61: 435-438.

Hertog MGL, Hollman PCH, Katan MB, 1992. Content of potentially anticarcinogenic flavonoids of 28 vegetables and 9 fruits commonly consumed in The Netherlands. J. Agr. Food Chem. 40:2379-2383. 
Holst B, Williamson G, 2008. Nutrients and phytochemicals: from bioavailability to bioefficacy beyond antioxidants. Curr. Opin. Biotech. 19:73-82.

Ierna A, Mauro RP, Mauromicale G, 2012. Biomass, grain and energy yield in Cynara cardunculus L. as affected by fertilization, genotype and harvest time. Biomass Bioenerg. 36:404-410.

Jimènez-Escrig A, Dragsted LO, Daneshvar B, Pulido R, Saura-Calixto F, 2003. In vitro antioxidant activities of edible artichoke (Cynara scolymus L.) and effect on biomarkers of antioxidants in rats. J. Agr. Food Chem. 51: 5540-5545.

Justesen U, Knuthsen P, 2001. Composition of flavonoids in fresh herbs and calculation of flavonoid intake by use of herbs in traditional Danish dishes. Food Chem. 73:245-250.

Justesen U, Knuthsen P, Leth T, 1998. Quantitative analysis of flavonols, flavones, and flavanones in fruits, vegetables and beverages by high-performance liquid chromatography with photo-diode array and mass spectrometric detection. J. Chromatogr. A 799:101110.

Kalt W, 2005. Effects of production and processing factors on major fruit and vegetables antioxidants. J. Food Sci. 70:11-19.

Karakaya S, Nehir S, 1999. Quercetin, luteolin, apigenin and kaempferol contents of some foods. Food Chem. 66:289-292.

Kinnula VL, Crapo JD, 2004. Superoxide dismutases in malignant cells and human tumors. Free Radical Bio. Med. 36:718-744.

Kirchhoff R, Beckers C, Kirchhoff GM, Trinczek-Gartner H, Petrowitz 0, Reiman HJ, 1994. Increase in choleresis by means of artichoke extract. Results of a randomized placebo-controlled double-blind study. Phytomedicine 1:107-115.

Kukić J, Popovi V, Petrovi S, Mucaji P, iri A, Stojkovi D, Sokovi M, 2008. Antioxidant and antimicrobial activity of Cynara cardunculus extracts. Food Chem. 107:861-868.

Lahoz I, Fernández JA, Migliarob D, Macuaa JI, Egea-Gilabertd C, 2010. Using molecular markers, nutritional traits and field performance data to characterize cultivated cardoon germplasm resources. Sci. Hortic.-Amsterdam 127:188-197.

Lanteri S, Saba E, Cadinu M, Mallica GM, Baghino L, Portis E, 2004. Amplified fragment length polymorphism for genetic diversity assessment in globe artichoke. Theor. Appl. Genet. 108:1534-1544.

Lattanzio V, 2003. Bioactive polyphenols: their role in quality and storability of fruit and vegetables. J. Appl. Bot. 77:128-146.

Lattanzio V, Cardinali A, Di Venere D, Linsalata V, Palmeri S, 1994. Browning phenomena in stored artichoke (Cynara scolymus L.) Heads or chemical reactions? Food Chem. 50:1-7.

Lattanzio V, Cicco N, Terzano R, Raccuia S, Mauromicale G, Di Venere D, Linsalata V, 2002. Potenziale utilizzo di sottoprodotti derivanti dalla lavorazione industriale del carciofo [Cynara cardunculus L. var. scolymus (L.) Fiori]: antiossidanti di natura fenolica ed inulina. pp 251-258 in Atti XIX Convegno SICA, Reggio Calabria, Italia.

Lattanzio V, Kroon PA, Linsalata V, Cardinali A, 2009. Globe artichoke: a functional food and source of nutraceutical ingredients. J. Funct. Food. 1:131-144.

Li Y, But PP, Ooi VE, 2005. Antiviralactivity and mode of action of caffeoylquinicacids from Schefflera heptaphylla (L.) Frodin. Antiviral Res. 68:1-9.

Llorach R, Espin JC, Tomas-Barberan FA, Ferreres F, 2002. Artichoke (Cynara scolymus L.) byproducts as a potential source of healthpromoting antioxidant phenolics. J. Agr. Food Chem. 50: 3458-3464.

Lombardo S, Pandino G, Mauro R, Mauromicale G, 2009. Variation of phenolic content in globe artichoke in relation to biological, technical and environmental factors. Ital. J. Agron. 4:181-189.

Lombardo S, Pandino G, Mauromicale G, Knödler M, Carle R, Schieber A, 2010. Influence of genotype, harvest time and plant part on polyphenolic composition of globe artichoke [Cynara cardunculus L. var. scolymus (L.) Fiori]. Food Chem. 119: 1175-1181.
Lombardo S, Pandino G, Ierna A, Mauromicale G, 2012. Variation of polyphenols in a germplasm collection of globe artichoke. Food Res. Int. 46: 544-551.

López-Molina D, Navarro-Martínez MD, Melgarejo FR., Hiner ANP, Chazarra S., Rodríguez-López JN, 2006. Molecular properties and prebiotic effect of inulin obtained from artichoke (Cynara scolymus L.). Phytochemistry 66: 1476-1484.

Lutz M, Henríquez C, Escobar M, 2011. Chemical composition and antioxidant properties of mature and baby artichokes (Cynara scolymus L.), raw and cooked. J. Food Compos. Anal. 24: 49-54.

Maccarone E, Fallico B, Fanella F, Mauromicale G, Raccuia SA, Foti S, 1999. Possible alternative utilization of Cynara spp. II. Chemical characterization of their grain oil. Ind. Crops Prod. 10: 229-237.

Manach C, Scalbert A, Morand C, Rémésy C, Jimenez L, 2004. Polyphenols: food sources and bioavailability. Am. J. Clin. Nutr. 79: 727-747.

Manach C, Williamson G, Morand C, Scalbert A, Rémésy C, 2005. Bioavailability and bioefficacy of polyphenols in humans. I. Review of 97 bioavailability studies. Am. Soc. Clin. Nutr. 81: 230S-242S.

Martin-Diana A.B., Rico D., Frias J.M., Barat J.M., Henehan G.T.M., Barry-Ryan C, 2007. Calcium for extending the shelf life of fresh whole and minimally processed fruits and vegetables: A review. Trends Food Sci. Tech. 18: 210-218.

Mauromicale G, Ierna A, 2000. Panorama varietale e miglioramento genetico del carciofo. Inform. Agr. 56: 39-45.

McDougall B, King PJ, Wu BW, Hostomsky Z, Reinecke MG, Robinson WE, 1998. Dicaffeoylquinic and dicaffeoyltartaric acids are selective inhibitors of human immunodeficiency virus type 1 integrase. Antimicrob. Agents Chemother. 42: 140-146.

Mertens-Talcott SU, Rios J, Jilma-Stohlawetz P, Pacheco-Palencia LA, Meibohm B, Talcott ST, Derendorf H, 2008. Pharmacokinetics of anthocyanins and antioxidant effects after the consumption of anthocyanin-rich acai juice and pulp (Euterpe oleracea Mart.) in human healthy volunteers. J. Agric. Food Chem. 56: 7796-802.

Moglia A, Lanteri S, Comino C, Acquadro A, De Vos R, Beekwilder J, 2008. Stress-induced biosynthesis of dicaffeoylquinic acids in globe artichoke. J. Agric. Food Chem. 56: 8641-8649.

Nakajima Y, Shimazawa M, Mishima S, Hara H, 2007. Water extract of propolis and its main constituents, caffeoylquinic acid derivatives, exert neuroprotective effects via antioxidant actions. Life Sci. 80: 370-377.

Pandino G, Courts FL, Lombardo S, Mauromicale G, Williamson G, 2010. Caffeyolquinic acids and flavonoids in the immature inflorescence of globe artichoke, wild and cultivated cardoon (Cynara cardunculus L.). J. Agr. Food Chem. 58: 1026-1031.

Pandino G, Lombardo S, Mauromicale G, 2011a. Chemical and morphological characteristics of new clones and commercial varieties of globe artichoke (Cynara cardunculus var. scolymus). Plant Foods Hum. Nutr. 66: 291-297.

Pandino G, Lombardo S, Mauromicale G, Williamson G, 2011b. Phenolic acids and flavonoids in leaf and floral stem of cultivated and wild Cynara cardunculus L. genotypes. Food Chem. 126: 417-422.

Pandino G, Lombardo S, Mauromicale G, Williamson G, 2011c. Profile of polyphenols and phenolic acids in bracts and receptacles of globe artichoke (Cynara cardunculus var. scolymus) germplasm. J. Food Compos. Anal. 24: 148-153.

Pandino G, Lombardo S, Mauro RP, Mauromicale G, 2012. Variation in polyphenol profile and head morphology among clones of globe artichoke selected from a landrace. Sci. Hort. 138: 259-265.

Peschel W, Sànchez-Rabaneda F, Diekmann W, Plescher A, Gartzìa I, Jiménez D, Lamuela-Raventòs R, Buxaderas S, Codina C, 2006. An industrial approach in the search of natural antioxidants from vegetable and fruit wastes. Food Chem. 97: 137-150.

Petrowicz 0, Gebhardt R, Donner M, Schwandt P, Kraft K, 1997. Effects 
of artichoke leaf extract on lipoprotein metabolism in vitro and in vivo. Atherosclerosis 129: 147.

Pietta P, 2000. Flavonoids as antioxidants. J. Nat. Prod. 63: 1035-1042.

Pinelli P, Agostini F, Comino C, Lanteri S, Portis E, Romani A, 2007. Simultaneous quantification of caffeoyl esters and flavonoids in wild and cultivated cardoon leaves. Food Chem. 105: 1695-11701.

Rico D, Martin-Diana AB, Barat JM, Barry-Ryan C, 2007. Extending and measuring the quality of fresh-cut fruit and vegetables: A review. Trends Food Sci Tech. 18: 373-386.

Romani A, Pinelli P, Cantini C, Cimato A, Heimler D, 2006. Characterization of Violetto di Toscana, a typical Italian landrace of artichoke (Cynara scolymus L.). Food Chem. 95, 221-225.

Rossoni G, Grande S, Galli C, Visioli F, 2005. Wild Artichoke Prevents the Age-Associated Loss of Vasomotor Function. J. Agric. Food Chem. 53: 10291-10296.

Sànchez-Rabaneda F, Jàuregui 0, Lamuela-Raventós RM, Bastida J, Viladomat F, Codina C, 2003. Identification of phenolic compounds in artichoke waste by high-performance liquid chromatographytandem mass spectrometry. J. Chromatog. A. 1008: 57-72.

Schütz K, Kammerer D, Carle R, Schieber A, 2004. Identification and quantification of caffeoylquinic acids and flavonoids from artichoke (Cynara scolymus L.) heads, juice, and pomace by HPLCDAD-ESI/MS ${ }^{n}$. J. Agric. Food Chem. 52: 4090-4096.

Schütz K, Persike M, Carle R, Schieber A, 2006. Characterization and uantification of anthocyanins in selected artichoke (Cynara scolymus L.) cultivars by HPLC-DAD-ESI-MS ${ }^{n}$. Anal. Bioanal. Chem. 384: 1511-1517.

Shahidi F, 1997. Natural antioxidants: an overview. In: Shahidi F, Natural antioxidants: Chemistry, health effects and applications, (pp. 1-7). Champaign, IL: AOCS Press.

Sharaf-Eldin MA, Schnitzler WH, Nitz G, Razin AM, El-Oksh II, 2007. The effect of gibberellic acid $\left(\mathrm{GA}_{3}\right)$ on some phenolic substances in globe artichoke (Cynara cardunculus var. scolymus (L.) Fiori). Sci. Hortic. 111: 326-329.

Shirley BW, 1996. Flavonoid biosynthesis: 'new' functions for an 'old' pathway. Trends Plant Sci. 31: 377-382.

Shukla S, Gupta S, 2010. Apigenin: A Promising Molecule for Cancer
Prevention. Pharm. Res. 27:962-978

Slanina J, Taborska E, Bochorakova H, Slaninova I, Humpa 0, Robinson WE, Schram KH 2001. New and facile method of preparation of the anti-HIV-1 agent, 1,3-dicaffeoylquinic acid. Tetrahedron Letters 42 : 3383-3385.

Todaro A, Peluso 0, Catalano AE, Mauromicale G, Spagna G, 2010. Polyphenol oxidase activity from three Sicilian artichoke [Cynara cardunculus L. var. scolymus L. (Fiori)] cultivars: studies and technological application on minimally processed production. J. Agric. Food Chem. 58: 1714-1718.

Tomás-Barberán F, Espín JC, 2001. Phenolic compounds and related enzymes as determinants of quality in fruits and vegetables. J. Sci. Food Agric. 81: 853-876.

Valentão P, Fernandes E, Carvalho F, Andrade PB, Seabra RM, Bastos ML, 2002. Antioxidative properties of cardoon (Cynara cardunclus L.) infusion against superoxide radical, hydroxyl radical, and hypochlorous acid. J. Agric. Food Chem. 50: 4989-4993.

Van Acker SABE, Van Den Berg D, Tromp MNJL, Griffioen DE, Van Bennekom WP, Van Der Vijgh WJF, Bast A, 1996. Structural aspects of antioxidant activity of flavonoids. Free Radical Bio. Med. 20: 331342 .

Vinson JA, Dabbagh YA, Serry MM, Jang J, 1995. Plant flavonoids, especially tea flavonols, are powerful antioxidant using an in vitro oxidation model for heart disease. J. Agric. Food Chem. 43: 2800-2802.

Wang H, Cao G, Prior R, 1997. Oxygen radical absorbing capacity of anthocyanins. J. Agric. Food Chem. 45: 304-309.

Wang M, Simon JE, Aviles IF, He K, Zheng QY, Tadmor Y, 2003. Analysis of antioxidative phenolic compounds in artichoke (Cynara scolymus L.). J. Agric. Food Chem. 51: 601-608.

Wiklund A, 1992. The genus Cynara L. Bot. J. of Lin. Soc. 109: 75-123.

Williamson G, Barron D, Shimoi K, Terao J, 2005. In vitro biological properties of flavonoid conjugates found in vivo. Free Radical Res. 39: 457-469.

Zhu X, Zhang H, Lo R, 2004. Phenolic compounds from the leaf extract of artichoke (Cynara scolymus L.) and their antimicrobial activities. J. Agric. Food Chem. 52: 7272-7278. 